\title{
Study on Influence to The Overglaze colors by Low-carbon Catalytic Combustion Furnace of Natural Gas
}

\author{
Meixian $\mathrm{Wei}^{1, \mathrm{a}}$, Tianyu Bai ${ }^{2, \mathrm{~b}}$, Qiusi Zhang ${ }^{3, \mathrm{c}}$, Shihong Zhang ${ }^{4, \mathrm{~d}}$ \\ ${ }^{1}$ School of Environment and Energy Engineering,Beijing \\ University of Civil Engineering and Architecture, 100044, China \\ ${ }^{2}$ School of Environment and Energy Engineering, Beijing \\ University of Civil Engineering and Architecture, 100044, China \\ ${ }^{3}$ School of Environment and Energy Engineering, Beijing \\ University of Civil Engineering and Architecture, 100044, China \\ ${ }^{4}$ School of Environment and Energy Engineering, Beijing \\ University of Civil Engineering and Architecture, 100044, China \\ aemail: \\ 2294394859@qq.com, bemail:754477842@qq.com, ${ }^{\mathrm{C} e m a i l}: 604052084 @ q q . c o m,{ }^{\mathrm{d}}$ email:shihongzha \\ ng@bucea.edu.cn
}

Keywords: Catalytic combustion; Particulate Matter; Overglaze color;Low pollution

\begin{abstract}
Compared with conventional combustion, catalytic combustion as a developing technology could make the pollutants emissions to zero. The experimental studies and theoretical analysis have been involved in this essay to study on if catalytic combustion furnace can burn overglaze color.In this paper, by using natural gas catalytic combustion furnaces on firing overglaze color, it gets conclusions that the natural gas catalytic combustion furnaces meet the requirement on firing glaze color process and have the characteristics of low pollution. The research results show that overglaze color which uses furnace and the process of catalytic combustion of natural gas shows scene more sterling with stability,the surface of that is smooth and bright, stable colouration,overall looks soft and light.
\end{abstract}

\section{Introduction}

Air pollution is a critical environmental issue for China, which is also a global problem with far-reaching environmental impacts. Recent epidemiologic studies have shown that ambient air pollution exposure is associated with increased mortality and higher incidence diseases such as asthma, chronic obstructive pulmonary disease, and cancer ${ }^{[1]}$. When the first scientist examined the effect of air pollution on health after the Meuse Valley fog in 1930 (Firket, 1936) or the London smog in 1952 (Ministry of health, 1954), no one could have known what an extended field of research they started ${ }^{[2]}$.

Conventional overglaze color on the firing technology are mostly using coal or gas as fuel .The combustion of hydrocarbons contributes to a large part of air pollutant and the formulation of particulate matter(PM), however, catalytic combustion as an emerging combustion technology is certified with zero pollutant emissions.Catalytic combustion technology not only in eliminating pollution, environmental protection shows the unique advantages, but also very effective in terms of energy savings ${ }^{[3,4]}$.To better understand the environmental effects of catalytic combustion, a study was conducted. In this article ,it mainly studied the characters of overglaze color which is fired by using catalytic combustion furnaces,including the temperature of furnace,constituent of catalytic combustion exhaust and the apparent characteristics of glaze color. 


\section{Experimental set-up}

As a new catalytic combustion furnace combustion device, from the source to prevent and control pollution and protect the ecological ${ }^{[5]}$.And the catalytic gas burner used with condensing boiler, can greatly improve the boiler thermal efficiency and has the advantages of near zero emissions $^{[6]}$.

Figure 1. presents the conventional diagram about the equipment.The core of the system is the catalytic combustion furnace, whose size is $0.4 \mathrm{~m}$ long, $0.1 \mathrm{~m}$ high and $0.8 \mathrm{~m}$ wide.The furnace body is connected to the catalytic burner. The support for all the monoliths tested here was cordierite. The two square catalytic honeycomb monoliths were installed in the burner each time. The right part of burner is connected with a section of pipe, which is the mixture of air and gas.The control of air and gas respectively have their own independent reading device. The natural gas and air are regulated via GMS0050BRSN200000 natural gas meter and CMG400A080100000 air meter with 0 50L/min and $0 \sim 80 \mathrm{~m}^{3} / \mathrm{h}$ of full-scale range respectively. The two meters are provided electric current.

Materials used in this experiment are ordinary white porcelain,whose surface are decorated with colorful paintings, and then put them into the kiln to fire.Before the experiment,run the fan blowing on furnace,to exclude the interference of the residual gas in the chamber of a stove or furnace last time.Then start the burner in the excess air ratio of 1.3. And in the experiment,the temperature parameter was recorded by digital thermometer,offering the information of the temperature of the furnace center position.Then write down the firing time and temperature.According the temperature change to determine the best time to close the door when fired overglaze color.To supplement the data, mixed gas in the furnace is analysed by the exhaust gas analyser.During the experiment, record the time, temperature and the concentration of catalytic combustion exhaust.

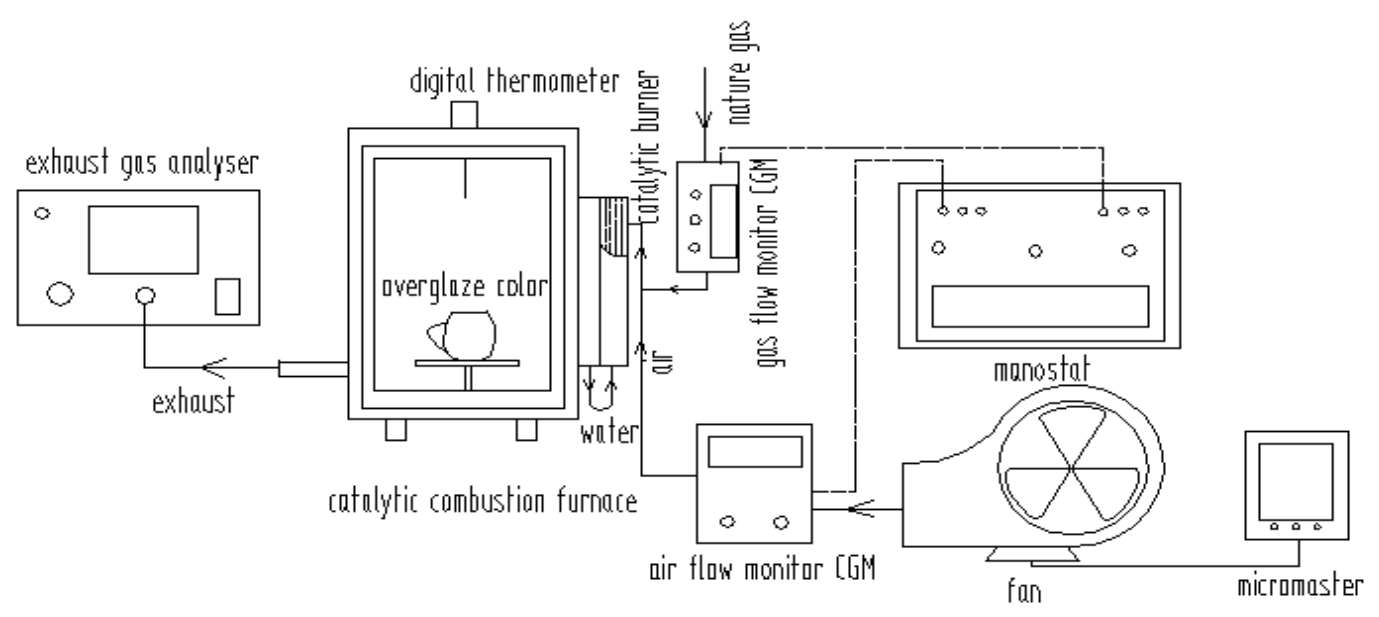

Fig.1. The experimental results

\section{Result and Discussion}

Figure 2. shows how temperature and composition of emission gas changed when the experiment operating.In picture a,it illustrates that temperature rose slowly as time goes by.The slowly rising temperature has promoting effect to the firing of glaze color, especially for the combination of pigment and glaze. Picture b,the content of CO and NO,first increasing and then decreasing.The concentration of CO is at about 20ppm,while national emission limit value is $160 \mathrm{ppm}$, which is much larger than that .In addition, the maximum concentration of NO is 26ppm,which is match up to integrated emission standard of air pollutants ${ }^{[7]}$. When it came to the 120 minute in experiment, the pollutant decreased sharply, achieving zero pollutant emission.That is to say that CO and NO concentration is basic not decrease before the 120 minute, then the content of CO and NO are greatly reduced until a stable state.So in this experiment,it fully reflect that the characteristics of natural gas catalytic combustion furnaces near zero pollutant emissions. 


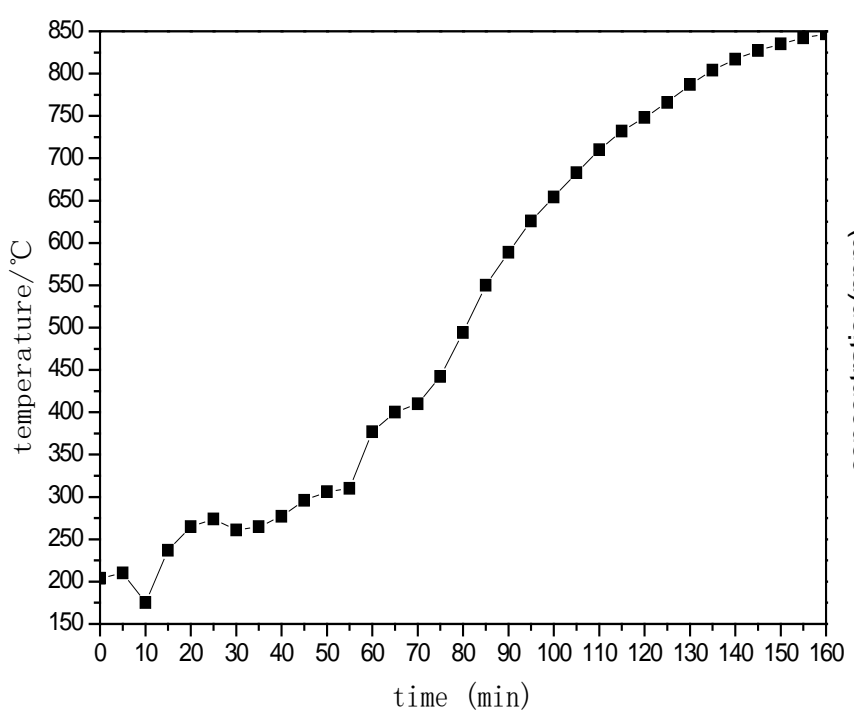

(a) The variation of temperature

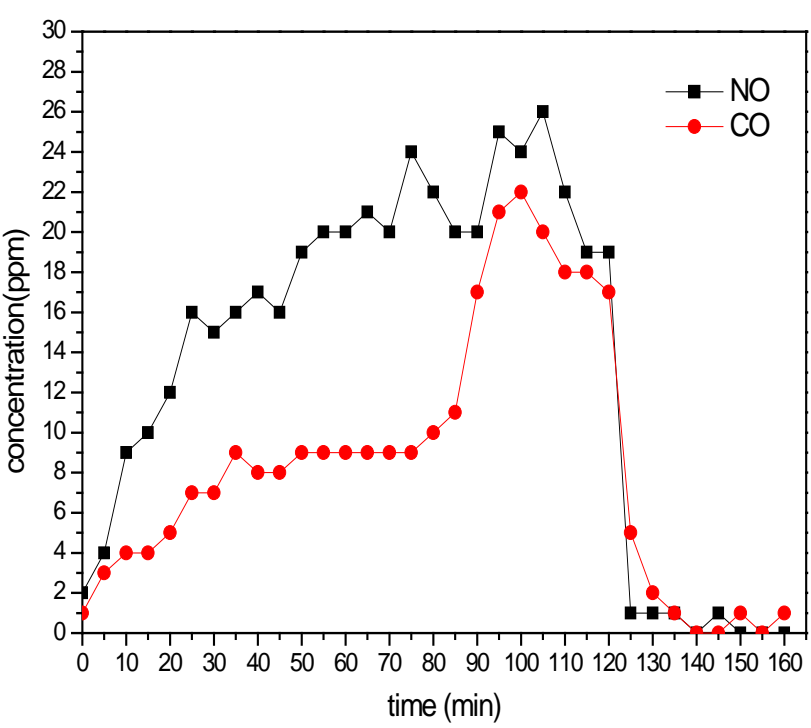

(b) The variation of exhaust gas constituent

Fig.2. The variation of temperature, constituent of catalytic combustion exhaust

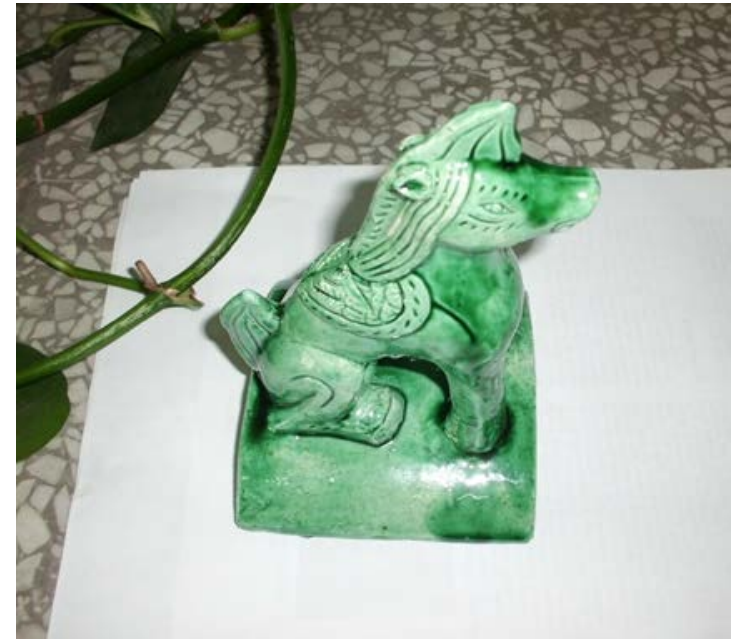

(a) The coloured glaze

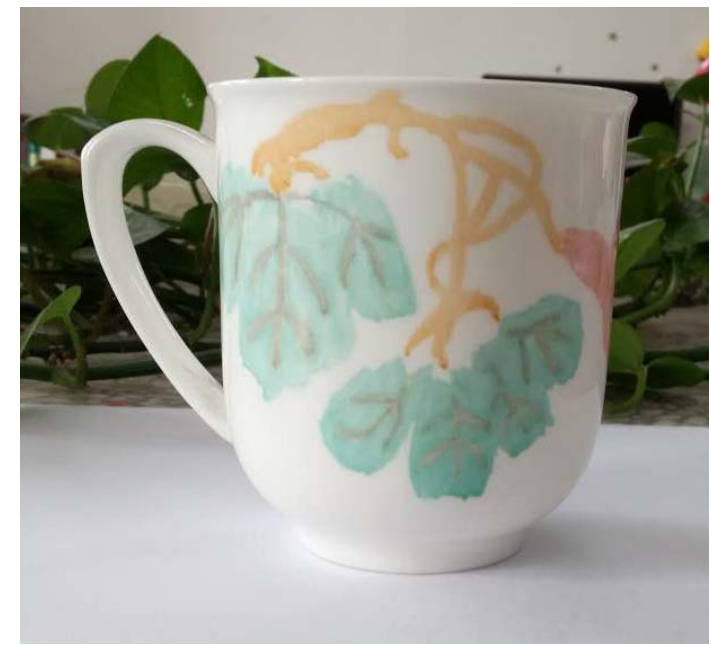

(b) The overglaze color

Fig.3. The finished product which are fired by natural gas catalytic combustion furnaces

In order to further study the burning effect of natural gas catalytic combustion furnace,this experiment not only fired the glaze color,the glazed products were also fired.As is shown in figure 3,picture a is the coloured glaze products that is fired by natural gas catalytic combustion furnaces.It is in embryo with green colored glaze and fired into the furnace.Look from the appearance,green, glittering and transparent;modelling lively and vivid.But the overall color shades,this is because colored glaze melt and flow in the firing process. This will not only do not affect the overall effect of the firing of finished products,but give a fresh visual effect,and has a strong artistic.

Picture b,it is the overglaze color which is fired by natural gas catalytic combustion furnaces.It is decorated with yellow, green and red colors.From the color point of view,the overall color is elegant and moist, warm and natural.Look from the appearance,the glaze and pigment combine closely,also the surface is smooth and bright.This is because the natural gas catalytic combustion furnace radiates outward in the way of high temperature radiation.So the surface of overglaze color which is fired by the furnace is heated evenly,overall looks soft and light.However, due to the embryo, pigments and painting techniques, the overglaze color that is fired in this experiment may not be comparable with the glaze on the market,the overall visual effect is still a lot of good place.

\section{Conclusion}

The following conclusions from the results of the study on whether natural gas catalytic 
combustion furnaces can burn overglaze color. It was found that catalytic combustion furnaces meet the technological requirements on firing overglaze color. And it hardly pollute the environment, exhaust gas can achieve near-zero emissions at the end of the the experiment, in line with the green economy development of our country at present.Also the overglaze color that is fired has steady color and bright luster.Its surface effect looks soft and light.So, under the background of global increasingly serious environmental pollution,vigorously promote the catalytic combustion furnace and make it apply to the overglaze color of the market not only can ease the current air pollution situation but also make the traditional splendid technology of overglaze color get inheritance,it is an important direction for the development of the catalytic combustion furnaces in the future.

\section{Acknowledgement}

The project was sponsored by the Beijing Municipality Key Lab of Heating, Gas Supply, Ventilating and Air Conditioning Engineering and Collaborative Innovation Center of Key Technologies of Energy Saving and Emission Reduction.

\section{References}

[1] J. Cohen, et al., The Global Burden of Disease Due to Outdoor Air Pollution, Journal of Toxicology and Environmental Health, Part A: Current Issues, Vol. 68, No. 13-14, 2005, pp. 1301-1307. doi:10.1080/15287390590936166

[2] Regina Rückerl, Alexandra Schneider, Susanne Breitner, Josef Cyrys, and Annette Peters, Health effects of particulate air pollution: A review of epidemiological evidence, Inhalation Toxicology, 2011; 23(10): 555 - 592

[3] National Bureau of Technical Supervision. Domestic gas standard [S]. 1997-03-01.

[4] Chengxi Zhou. Gas infrared emitters [M]. BJ: China Building Industry Press,1982.

[5] Shihong Zhang, Dupont Valerie, Williams Alan, Rickett Gavin. Mechanisms and Applications of Catalytic Combustion of Natural Gas in the Presence of Sulphur Compounds. BJ: The Science Press. 2010,56-88

[6] Shihong Zhang, Lin He, Wei Sun. The Theory and Applications of Catalytic Combustion of Natural Gas.

[7] DB11/501-2007, Integrated emission standard of air pollutants[S]. 